\title{
ENCENAÇÃO AUTORAL, TEXTUAL E SUA TRADUÇÃO: O AVENTUROSO SIMPLICISSIMUS (1668/9)DE HANS JACOB CHRISTOFFEL VON GRIMMELSHAUSEN
}

\author{
AUTHORIAL AND TEXTUAL STAGING AND ITS TRANSLA- \\ TION: O AVENTUROSO SIMPLICISSIMUS (1668/9)BY HANS JACOB \\ CHRISTOFFEL VON GRIMMELSHAUSEN
}

Michael Korfmann ${ }^{1}$, Raquel Meneguzzo ${ }^{2}$

Resumo: O presente artigo aborda, primeiro, o romance de Grimmelshausen sob o aspecto da encenação autoral e textual. Ele parte da multiperspectividadedo autor, escondida através de diversos anagramas de seu nome, para depois analisar o caráter textual como tecido polifônico complexo de transposições literais, alusões indiretas e rupturas irônicas com padrões de gêneros tradicionais. O estudo concebe a obra em questão como compêndio dos discursos de seu tempo que não os segue de maneira cega, mas toma a liberdade de uma orquestração própria de vozes. Assim, resulta em uma encenação ambígua, uma reflexão satírica a partir de citação, inserção ou transposição de referências externas, sem oferecer uma leitura ou moral conclusiva. Pergunta também, num segundo momento, como a tradução para o português procedeu para fazer jus à riqueza linguística deste recorte histórico.

Palavras-chave: O Aventuroso Simplicissimus; Grimmelshausen; encenação; tradução.

Abstract: This article first discusses the novel by Grimmelshausen from the aspect of authorial and textual staging. It focuses on the authorial multiperspectiveness through numerous anagrams and then analyzes the textual character as a complex polyphonic literal transposition, full of indirect allusions and ironic breaks with traditional genre patterns. The study conceives the work in question as a compendium of speeches of his time which it does not follow blindly, but takes the liberty of an own orchestration of voices. Thus, it results in an ambiguous scenario, a satirical reflection from quotation, insertion or transposition of external references without offering a conclusive final

1 Pós-doutor pela Universidade de Bonn e Bochum, Alemanha. Professor associado da UFRGS.

2 Estudante de graduação/bolsista DAAD da Universidade de Erlangen/Alemanha. 
reading. The article also investigates how the translation into Portuguese proceeded to live up the linguistic richness of this historical compilation. Keywords: Simplicissimus; Grimmelshausen; staging; translation.

\section{Introdução}

Dos autores e obras da literatura do século XVII, certamente apenas dois nomes têm ainda maior relevância fora dos círculos acadêmicos: Andreas Gryphius (1616-1664) com sua poesia, e Hans Jacob Christoffel von Grimmelshausen (1621-1676) com seu romance O Aventuroso Simplicissimus, traduzido em 2008 para o português por Mario Luiz Frungillo.

Publicado originalmente em 1668 em cinco livros, Simplicissimus conta, a princípio em primeira pessoa e de maneira retrospectiva, sua vida turbulenta no âmbito histórico da Guerra dos Trinta Anos (1618-1648). Mas o faz através de um narrador não confiável, "a most deceptive witness whose credentials as na autobiographer are questionable" (AYLETT, 1989, p. 162). Um ano mais tarde, foi acrescentada ainda uma sexta parte com o nome de "Continuatio" no qual o protagonista retoma suas viagens e acaba, ao final, numa ilha deserta como náufrago. Os últimos três capítulos são narrados não mais em primeira pessoa, mas através da perspectiva do capitão de um navio holandês que encontra o eremita radicado na ilha e esse entrega ao navegador os manuscritos de suas aventuras. O romance foi elogiado por escritores como Clemens Brentano, que o classificou como "um dos livros mais magistrais" e "obra divina"; Joseph von Eichendorf considerou o romance "provindo diretamente do povo" e acrescenta que "é um prazer acompanhar como Grimmelshausen consegue dar vazão a este mundo bestial com senso de humor"3 (KAISER s.d.). Thomas Mann, em 1944, num breve prefácio à primeira edição sueca do romance, apresentava-o como raríssimo monumento literário, obra magnificente e imortal "da mais rigorosa grandeza, colorida, selvagem, crua, divertida, apaixonada e aviltada, fervilhante de vida, familiarizada com a morte e com o diabo, em seu desfecho contrita, e inteiramente cansada de um mundo que se esvai em sangue, roubo e volúpia" (apud MAZZARI, 2009, s.p.), e se conhece há tempo as influências de Grimmelshausen sobre Bertholt Brecht e Günther Grass.

A inserção cultural de Simpliccisimus se apresenta ainda na revista satírica de mesmo nome, editada entre 1896 e 1944, que cita na primeira edição

3 As traduções de língua alemã foram feitas pelos autores. 
uma frase deGrimmelshausen - „Es hatmirsowollenbehagen, / MitLachen die Wahrheitzusagen" (algo como: 'Me fez muito bem dizer a verdade em meio aoriso') - como lema da publicação e que contava com autores renomados como Hermann Hesse, Hugo von Hofmannsthal ou o próprio Thomas Mann. Foram produzidas também, entre 1963 e 2000, quatro peças radiofônicas baseadas no romance, bem como edições em audiolivros, e uma longa versão televisiva em quatro capítulos em 1975, com direção de Fritz Umgelter. Em 2009, Reinhardt Kaiser traduziu o Simplicissimus do alemão do século XVII para uma linguagem contemporânea. A editora Eichborn, num texto publicitário, justifica tal transposição, afirmando que Reinhard Kaiser reintroduziu reanimou esse primeiro grande livro popular através de uma linguagem atual: "Ele conseguiu a façanha de tornar novamente presente o ritmo, o tom e o espírito do texto original, sua profundidade e seu humor extraordinário, captando de forma excepcional um romance que é, ao mesmo tempo, um romance social, cômico, pícaro e histórico; um relato de guerra, uma sátira, romance de aventura, de formação, uma grotesca erótica, uma robinsonada e um relato de viagem"(KAISER, s.d.).

O próprio Kaiser oferece dois motivos básicos para seu trabalho: primeiro, atualizar palavras e expressões em desuso ou com conotações diferentes, como a palavra etliche, que hoje significa "vários" ou "muitos", mas na época de Grimmelshausense referia a "poucos"; o segundo diz respeito a obstáculos para uma leitura fluente, como, por exemplo, formas antigas de palavras e de estruturas gramaticais, bem como certo desordenamento estrutural devido à falta de sinais de pontuação ou parágrafos, o que torna a leitura do original bastante estacada. Reconhece que, com tais atualizações, certos elementos desaparecem, mas por outro lado outros reaparecem ou se "tornam novamente visíveis, o que facilita a aproximação entre obra e leitor” (KAISER, 2008, p. 719).

O que torna o romance ainda hoje uma obra desafiadora e quase um precursor da literatura moderna é sem dúvida seu caráter multifacetado, a mistura de diversos níveis narrativos ou linguísticos, e sua técnica de se apropriar de fontes autobiográficas, literárias, históricas e enciclopédicas. Tal recepção se diferencia da que houve no romantismo, na época de sua redescoberta. Vimos que Eichendorf enfatizou a origem popular de Simplicissimus, e há uma longa tradição de julgar Grimmelshausen como poeta-agricultor (Bauerndichter), ou seja, alguém que emerge desta camada social e nela encontra seu público alvo. Encontramos tal definição, por exemplo, em Scholte, que fala no "talento autodidata do poeta agricultor" (apud KÖNNEKE, 1928, p. 330). Oeftering viu sua obra "a serviço do povo" 
(1925, p. 538), Brie consta que a "base de sua postura e convicção está ligada ao universo camponês" (1938, p. 9) e Domagalla fala de "raízes folclórico-populares"(1942, p. 36). Mas mesmo na obra de Grimmelshausen que mais se situa neste âmbito, Der EwigwährendeKalender (O calendário perpétuo), não encontramos "sabedorias" referentes à vida no campo extraídas dos próprios camponeses, mas fortes intertextualidades com outras obras, sobretudo com o Calendarium perpetuum (1608), de Johann Colerus, do qual Grimmelshausen transcreve e reformula parte de seu próprio calendário (KOSCHLIG, 1997, p. 122-123). O mesmo acontece em Wundergeschichten-Kalender coma inclusão de motivos e narrativas da ArsApophthegmatica (1655), de Georg-PhilippHarsdörfer (KOSCHLIK, 1997, p. 174).

Andreas Merzhäuser (2004, p. 9) chamou tal procedimento ou encenação textual de montagem avantlalettre e, com isso, segue de certa forma o pensamento de Bürger (1987), que havia interligado o princípio da montagem ao emblema barroco. Mas diferente desta técnica vanguardista do início do século XX, oriunda sobretudo do desafio tecnológico-medial e que torna visíveis as fontes de sua "explosivemixtureofdifferent points ofviewsandlevels" (RICHTER, 1965, p. 116), Grimmelshausen frequentemente 'devora' suas inúmeras referências num ato quase antropofágico, não apenas textual, mas também autoral, através de diversos anagramas de seu nome, responsáveis pela criação de seu universo literário 'simplicianista'.

Assim, pretendemos abordar Simplicissimusprimeiro soba perspectiva de uma obra que, em sua encenação, transgride diversas referências textuais e autorais, e então avaliaremos se tais procedimentos podem ser vistos como precursores de programáticas e praxes vanguardistas. Obviamente, a diversidade dos elementos linguísticos citados, transpostos e trabalhados, que são constitutivos para o romance de Grimmelshausen, apresentam uma dificuldade a mais para o trabalho tradutório. Por isso, investigaremos num segundo momento como essa tarefa foi realizada na tradução para o português, e que técnicas o tradutor utilizou para fazer jus à riqueza do texto de partida.

\section{Encenação autoral e textual}

Grimmelshausen publicou apenas três textos (os romances históricos das lendas de DietwaltundAmelinde e ProximusundLympida, bem como o tratado ZweyköpffigerRatio Status) com seu nome verdadeiro. Outras obras foram publicadas de forma anônima, enquanto para as restantes publicações usava pseudônimos, quase sempre em forma de anagrama para 
Christoffel von Grimmelshausen: os mais conhecidos são GermanSchleifheim von Sulsfort; Melchior Sternfels von Fuchshaim; Samuel GreifnsonvomHirschfeld; PhilarchusGrossus von Trommenheim; Michael Rechulin von Sehmsdorff; Erich Stainfels von Grufensholm ou Simon Leugfrisch von Hartenfels. Apenasem 1838, Echtermeyer "finally solved the riddle and identified Grimmelshausen(...) as we know him today, as the author of an oeuvre" (OTTO, 2003, p.4). Este apagar de traços autênticos se reflete não apenas na autoria fictícia da edição original deSimplicissimus, onde consta um anagrama de Grimmelshausen (GermanSchleifheim von Sulsfort) como escritor desta obra, mas também lê-se, como local de impressão, o fictício "Monpelgart" (ainda escrito como "Mompelgart" na "Continuatio") e o também nome fictício "Johann Fillion" como responsável pela impressão e edição. Este provavelmente aponta para Johann Jon. Fil(ius), o filho mais velho do editor Wolff Eberhard Felßecker (KOSCHLIG, 1977, p. 36-40). Há ainda a inserção de "teusch" (alemão) no título, o que poderia levar à conclusão de que se trata, nesta obra, apenas da versão alemã de um livro estrangeiro. Apenas em 1838 foi possível atribuir essas obras ao autor Grimmelshausen, seguindo-se os apontamentos nos próprios textos para decifrar os diversos pseudônimos. Explicamos a encenação autoral em Grimmelshausenatravés do últimoparágrafo do Simplicissimus, na "Continuatio" (GRIMMELSHAUSEN, 2008, p. 645), onde o narrador se dirige ao leitor com a seguinte observação:

EXCELENTÍSSIMO, muito benévolo e caro leitor etc. este Simplicissimus é obra de Samuel Greifnson, de Hirschfeld, e não foi esta a única obra que eu encontrei depois de sua morte entre os escritos que ele deixou. Ele mesmo se refere neste livro ao Casto José de sua autoria e, em seu Peregrino satírico, a este seu Simplicissimus, que ele escreveu em parte durante sua juventude, quando ainda era um mosqueteiro. Desconheço, porém, o motivo pelo qual ele mudou seu nome trocando a ordem das letras e escreveu na folha de rosto GermanSchleifheim von Sulsfort. Ele deixou ainda finas poesias satíricas que, se a presente obra for apreciada, possivelmente serão também trazidas a lume em letra impressa. Não quis esconder do leitor esta informação. Não quis também deixar de fazer esta conclusão, pois ele, quando ainda vivia, já fizera imprimir as cinco primeiras partes. Que o leitor passe bem.

Dado em Rheinnec de 22 de abril, Anno 1668.

H.J.C.V.G.

P. zu Cernhein 
A abreviatura no final podemos hoje identificar como Hans Jacob Christoffel von Grimmelshausen, Praetor (prefeito) do município "zuCernhein", que remete ao município de Renichen, onde Grimmelshausen de fato exerceu tal função. Mas segundo a informação do texto citado, é Samuel Greifnson von Hirschfeld o autor de Simplicissimus, bem como do livro Casto Josée do Peregrino satírico. Os primeiros dois textos ele publicou com nome de "GermanSchleifheim von Sulsfort". Não é explicada a razão para a alteração do nome, mas aponta-se para a técnica do anagrama. Podemos ainda incluir outras três obras nesta rede anagrâmica: o Peregrino Satírico eDietwald e Amelinde, cuja autoria é atribuída ao protagonista de Simplicissimus no primeiro capítulo do segundo livro e no $19^{\circ}$ capítulo do terceiro livro, respectivamente; e, ainda, o Ewig-währendeCalender, se levarmos em conta o nome de batismo de Simplicissimus, "Melchior Sternfels von Fuchsheim” (ver ROSENBERG, 2015, p. 35-64).

Estes autores fictícios nas diversas obras de Grimmelshausen se relacionam de maneira bastante complexa e contraditória. Referente à obra em questão, às vezes tem-se a impressão de que Simplicissimus e Grimmelhsausen são a mesma pessoa, em outros momentos de que Grimmelshausen usa a máscara de outro para atacar Simplicissimus. Assim constrói-se um quadro enigmático, no qual Grimmelshausen às vezes surge como autor, narrador ou comentador, enquanto outras vezes se esconde atrás do papel de Simpliccissimus. Este, por sua vez, surge como personagem nas obras Courasche, Springinsfeld, Vogelnest I, RathstübelPlutonise no Ewig-währendenCalender. Além disso, se apresenta como autor fictício das obras VerkehrteWelt, SatyrischerPilgram, Keusche Joseph, Musai, Beernhäutere Gauckel-Tasche, bem como do Ratio Statuse do Teutsche Michel. É mencionado nos livros Vogelnest IIe Bart-Krieg. Sendo assim, Simplicissimus é quase onipresente na obra de Grimmelshausen e une, através desta presença, os diversos textos que, por outro lado, se destacam pela polifonia de pontos de vista e opiniões das mais diversas.

Quase todas as camadas sociais tomam a palavra: a nobreza, os camponeses, o clero, comerciantes, acadêmicos, artesãos, soldados, bem como pedintes ou ciganos. A perspectividade em Grimmelshausen se mostra no exemplo da figura da Courasche. No sexto capítulo do quinto livro de Simplicissimus há um encontro entre ambos, sem que ela seja apresentada com nome. Ela se sente tão aborrecida com sua descrição e caracterização nesta passagem, que apresenta sua própria versão e narrativa no capítulo 24 do romance Courasche, onde sua perspectiva sugere um decorrer muito diferente deste encontro. Esta disputa continua nos capítulos iniciais do 
romance Springinsfeld. Assim, há inúmeras opiniões, posições e perspectivas contrapostas, combinadas e colocadas umas contra outras. Um acontecimento é narrado, avaliado e comentado por diversos ângulos. Contribuem para esta multiperspectividade os diversos anagramas autorais, num jogo para confundir através de diferentes autorias fictícias e encenações das mesmas figuras em diversos textos com perspectivas também diversas. Simplicissimus é narrado em princípio a partir da perspectiva do protagonista como velho e sábio eremita, mas o texto toma a liberdade de, por vezes, se distanciar dos acontecimentos com um humor soberano, em outras ocasiões, de se identificar com o jovem Simplicissimus em suas diversas máscaras e papéis para, logo em seguida, se apropriar de posições, opiniões e perspectivas alheias em citações lúdicas. E, nos últimos três capítulos, há uma alteração completa do narrador, função agora assumida por Cornelius, comandante do navio holandês, que encontra Simplicissimus numa ilha deserta. Assim, eleva-se ainda mais o grau de dúvida referente à confiabilidade dos relatos.

Esta multiperspectividade, e, com isso, a incerteza e a ambuiguidade do mundo narrado (ou da narrativa deste mundo), é reforçada pela longa lista de diferentes papéis e discursos assumidos pela figura central: é filho de camponeses, pastor, aluno de eremita, serviçal, tolo, escrivão, cuidador de cavalos, fidalgo, comerciante, ajudante de médico, ator, doente, soldado do regimento de dragões, ladrão, peregrino, nobre, galeriano, escritor de romances, alquimista, viajante, místico, entre outros. Como viajante, atravessa a Alemanha, França, Rússia, Suíça, Itália, os países mediterrâneos até o oriente, e os mares pacíficos. No conflito religioso da Guerra dos Trinta Anos, muda do lado católico para o protestante e tem contato com a igreja ortodoxa na Rússia.

Há diversas tentativas de achar uma estrutura básica, uma rede construtiva que interligasse ou apoiasse tal diversidade. Friedrich Gundolf (1923), por exemplo, considera que os primeiros cinco livros seguem os tópicos da ignorância, tolice, pecado, pena e penitência; Jan Henrik Scholte(1950) defende que o romance se baseia estruturalmente no drama de cinco atos, e Weydt (1968) considera que toda essa diversidade social, local e discursiva se apoia na astrologia, pois o caminho do protagonista parte de "saturno, que rege sobre camponeses e eremitas, pobreza e estabilidade, passa pelo ameaçador e bélico marte, pelo sol, que fornece compreensão, por júpiter, que simboliza domínio, riqueza e sorte, por vênus, deusa não apenas do amor, mas também da música, pelo astuto e misterioso mercúrio, deus dos viajantes e ladrões, até a mutável lua” (apud BERGHAUS, BÜRGER et al. 
1976, p. 90), como se as sete características básicas do mundo e da vida criassem, assim, um contrapeso e uma rede essencial para encenar, dentro dela, as inúmeras máscaras, papéis, discursos e narrativas diferenciadas.

Mais promissor do que tais tentativas de subsumir as diversas facetas do romance, parece-nos justamente apontar para a multiplicidade discursiva e narrativa que pode ser detectada nas diversas fontes e influências textuais encenadas em Simplicissimus. Um primeiro estudo extenso referente a este aspecto foi realizado por GüntherWeydt(1968, p. 20-43). Podemos aqui apenas apontar para alguns exemplos mais recentes. Num âmbito geral, críticos como Thomas Strässel (2001) destacam certas semelhanças estruturais com o épico Parzival (por volta de 1200) de Wolfram von Eschenbach; ambos, em seu estado de tolice inicial, partem para o mundo a partir de seu isolamento na floresta. Ambas as crianças crescem como semi-órfãos e não têm inicialmente um nome próprio, apenas o recebem mais tarde através de eremitas parentes responsáveis também por sua formação. Ambos têm seu primeiro encontro com o mundo através de cavaleiros e iniciam suas vidas vestidos em roupas de tolos feitas de pele bovina. Obviamente, os destinos posteriores divergem bastante, pois não há uma comunidade do Santo Graal esperando pelo protagonista de Grimmelshausen. Mas há inserções ou empréstimos bem mais concretos. O primeiro trecho de Simplicissimus apresenta a queixa sobre as pessoas que não se contêm mais a suas limitações sociais:

Nestes nossos tempos (que muitos crêem serem os últimos) manifesta-se, entre gente de condição modesta, uma enfermidade cujos pacientes, tendo à custa de muito ralar e regatear juntado alguns tostões no bolso, e podendo vestir uma roupa ridícula, enfeitada com milhares de fitinhas de seda segundo a última moda, ou havendo-se tornado, por força de um acaso qualquer, independentes e conhecidos, logo pretendem se passar por senhores de vetusta estirpe cavalheiresca ou aristocrática. Acontece, porem, muitas vezes, que seus antepassados foram jornaleiros, carroceiros e carregadores; seus primos, muladeiros; seus irmãos, beleguins e esbirros; suas irmãs, putas; suas mães, alcoviteiras ou bruxas; in summa: que toda a sua linhagem, até a trigésima-segunda geração, está tão manchada e conspurcada quanto a corporação dos doceiros de Praga(GRIMMELSHAUSEN 2008, p. 15).

Trata-se, neste trecho, de uma citação quase literal do discurso 19 de uma famosa enciclopédia da época, a Piazza Universale: Das ist: 
AllgemeinerSchauplatz, MarcktundZusammenkunfftallerProfessionen, Künsten, Geschäfften, HändelnundHandwerckenઐc. Anjetzoaberauffstreulichsteverdeutscht de Thomas Garzoni (1659), bem como elementos adaptados do romance Der LandstörtzerGuzman von Alfarache, (1615), tradução de Aegidii Albertini da obra Guzmán de Alfarache, de MateoAlemán. A expressão "corporação dos doceiros de Praga" aponta, conforme Kaiser (GRIMMELSHAUSEN, 2009, p. 672), para um bando de ladrões formado por cozinhadores de açúcar em Praga no livro Historia von IsaakWinckelfelderundJobst von der Schneidt (1617) de Niclas Uhlenhardt, e a inserção "que muitos crêem serem os últimos" é expressão emprestada do já citado SatyrischerPilgram.

SilkeBeinssen-Hesse (2013) lista ainda as seguintes obras como claras referências integradas em Simplicissimus: Le Berger extravagante (162728) de Charles Sorels e sua versão de Georg PhilippHarsdörffer em Der wahnwitzigeSchäfer, parte da coletânea FrauenzimmerGesprächsspiele (1645), La VraieHistoirecomique, Francion (1623) de Charles Sorel eFlöhHatz, WeiberTratz (1577) de Johann Fischart.Grimmelshausen baseou-se ainda, segundo Beinssen-Hesse, em diversos relatos de viagem de Adam Olearius para narrar o episódio na Rússia e no tratado Liber de nymphis, sylphis, pygmaeis et salamandris et de caeterisspiritibus (1591), de Paracelso, para a passagem do Mummelsee com seus espíritos elementares. Há ainda empréstimos de Die lustigeSchaubühne von allerhandCuriositäten (1663) de Erasmus Franciscis, GesichtePhilanders von Sittewald (1640) de Hanß Michael Moscherosch ou os escritos sobre bruxas de São Remígio. Walter Holzinger (1969) aponta ainda para inserções de trechos da The Countess of Pembroke's Arcadia, conhecido também como Arcadia (final do século XVI), de Philip Sidney.

Simpliccisimus deve ser lido, então, como obra densa e polifônica, um tecido complexo de transposições literais, alusões indiretas e rupturas irônicas com padrões de gêneros tradicionais. Pode ser visto como um compêndio dos discursos de seu tempo que não segue tais discursos de maneira cega, mas toma a liberdade de uma própria orquestração de vozes. O conceito do romance como encenação ambígua, uma reflexão satírica a partir de citação, inserção ou transposição de referências externas já pode ser identificado no frontispício em forma de emblema, um fenômeno bastante difundido nas obras do século XVII. Lembramos que o emblema barroco consiste em um curto inscriptio como motto ou título, em uma pictura e em um subscriptio, com a função de enriquecer de maneira textual a combinação dos dois elementos anteriores.

Organon, Porto Alegre, v. 31, n. 61, p. 153-175, jul/dez. 2016. 


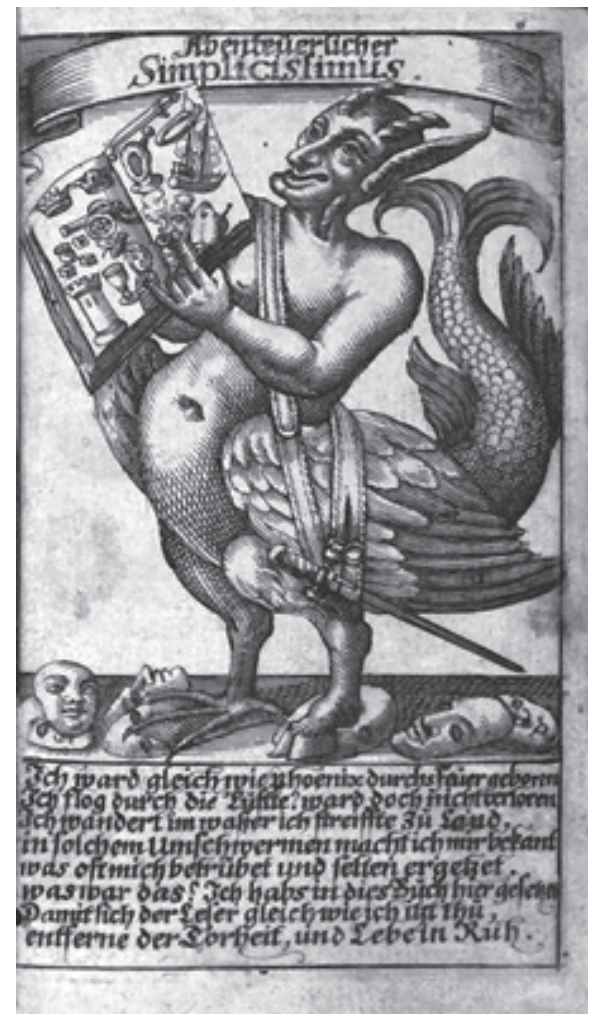

Figura 1: Frontispício da primeira edição de 1669

Tradução do subscriptio:

Como a Fênix lendária, do fogo eu nasci

Eu viajei pelo ar, jamais me perdi,

Caminhei sobre a terra, atravessei o mar

E esta errância só fez meu nome se espalhar

O que mais me deu dor do que meu deu prazer,

O que foi? Neste livro que dou a conhecer

Para que o seu leitor faça como eu agora:

Se afaste da loucura e viva onde a paz mora.

(GRIMMELSHAUSEN, 2008, p. iv)

O que se vê é uma figura meio homem, meio ser natural, composto por diversas espécies, e em sua mão, o livro de um mundo desarranjado, ilustrado com elementos da narrativa, como coroa, torre, dado, canhão, 
carapuça de tolos, navio à vela, árvore, espada e cidade, entre outros. A quimera ou ser híbrido, segura tal livro com a mão aberta em forma de Mano Cornuta, o que aponta, pelo menos, para dois significados: usava-se tal posição para se proteger contra forças do mal, mas também com expressão irônica no âmbito sexual, para designar ou falar de um "cornudo". A mesma ambiguidade entre o perigo - ou ameaça - e o debochado- ou sátiro -, caracteriza a expressão facial da figura. E as sete máscaras deitadas no chão e parcialmente pisoteadas podem ser vistas da mesma maneira ambígua: a quimera disfarça o teatro do mundo, tira-lhe suas máscaras para revelar a verdade, ou aponta para a mascarada autoral e textual do romance como elemento constitutivo? A mesma incerteza surge quando se analisa o frontispício num âmbito poetológico, pois aponta de forma bastante evidente para o início da Arte Poética (18 a. C.) de Horácio, onde este exige simplicidade e unidade da obra artística.

Se o pintor quisesse juntar a uma cabeça humana um pescoço de cavalo e a membros de animais de toda a ordem aplicar plumas variegadas, de forma a que terminasse em torpe e negro peixe a mulher de bela face, conteríeis vós o riso, ó meus amigos, se a ver tal espetáculo vos levassem? Pois crede-me, Pisões, em tudo a este quadro se assemelharia o livro, cujas ideias vãs se concebessem quais sonhos de doente, de tal modo que nem pés nem cabeça pudessem constituir uma só forma. Direi-vos que 'a pintores e a poetas igualmente se concedeu, desde sempre, a faculdade de tudo ousar'. Bem o sabemos, e por isso, tal liberdade procuramos e reciprocamente a concedemos, sem permitir, contudo, que à mansidão se junte a ferocidade e que se associem serpentes a aves e cordeiros a tigres (2012,p. 51-53).

Os elementos do ser apresentado no frontispício pertencem a diversos gêneros do mundo animal, dos homens e dos semideuses. Formam um todo, mas esse nega a harmonia através de "montagem" de partes não homogêneas entre si. Seria então o romance uma composição mista, uma negação do princípio de Horácio e uma enfática apologia à transgressão? É preciso ter certo cuidado pois, ao inserir o motivo do Sátiro, Grimmleshausen marca seu romance como literatura satírica (na sua época ainda se definiu este gênero como oriundo do ser híbrido mitológico), que desde a Antiguidade era considerada uma forma mais livre, não comprometida com as regras poéticas clássicas. Com isso, teríamos novamente uma unidade narrativa na qual Simplicissimus, de forma irônica (em meio ao riso), 
encena a história de sua vida em todas suas diferentes formas. O subscrito parece, à primeira vista, apontar nesta direção: a narrativa de sua vida é uma história de conversão, de uma existência perturbada, conflituosa, da "loucura" para a "paz" (GRIMMELSHAUSEN, 2008, p. iv). Aquilo que o 'eu' experimentou é narrado no livro para que o leitor, sob a impressão dos acontecimentos, consiga se distanciar da volatilidade vivida pelo protagonista. Mas uma leitura mais atenta mostra que suas instruções não são tão unívocas assim. Há contradições como "jamais me perdi" versus "errância", ou seja, uma caminhada sem destino. O 'eu' sólido é contraposto ao 'espalhar do meu nome’ e ainda há uma pergunta enigmática: “O que foi?”. Assim, temos aqui a mesma ambuiguidade tão característica no romance como todo. E tais oscilações entre olhares por vezes complementares, por vezes, contraditórios; entre uma retrospectiva homogênea e rupturas constantes e incompletas certamente contribuem para que este romance exerça seu fascínio até hoje. Investigamos a seguir como tal caráter multifacetado da obra foi transposto para português, ou seja, quais procedimentos e decisões tradutórias podem ser identificados na edição brasileira de 2008.

\section{A questão tradutória}

Muitas das referências textuais de Simplicissimus não são automaticamente resgatadas por leitores alemães, de modo que a edição de Breuer (2013), com o texto original, contém uma seção dedicada a elucidá-las, e, assim, as inúmeras alusões a outros textos podem ser consultadas. Kaiser (2009) manteve a seção em sua adaptação para o alemão contemporâneo; Frungillo (2008), no entanto, se valeu apenas de algumas dessas notas, que grafou ao rodapé das páginas ao longo do texto corrido. É possível afirmar, portanto, que muitos dos enigmas textuais de Grimmelshausen são ainda mais difíceis de serem decodificados na tradução brasileira. No entanto, Frungillo manteve gêneros textuais diferentes, ao traduzir poemas, por exemplo, e também diferenças de registro de linguagem, ao transcrever falas em dialetos e traduzi-las em notas de rodapé. Além do mais, resgata a diferença temporal através de escolhas lexicais, como "jornaleiro" (p. 15), no parágrafo de abertura, que não remete a entregador de jornais, já que na época eles não existiam, mas a pessoas que, diferente de escravos e servos, trabalhavam e recebiam pagamento por jornadas diárias de trabalho. $\mathrm{O}$ tom do texto, no entanto, não é arcaico, pelo contrário, a leitura é fluida como o fora para seus leitores do século XVII. 
Recorreremos a dois trechos para ilustrar como Frungillo lida com o caráter multifacetado de Simplicissimus em sua tradução para o português (2008).Uma das passagens escolhidas compararemos ainda à tradução de Kaiser (2009), e, por fim, abordaremos o papel do uso de notas de rodapé na tradução para o português.

No terceiro capítulo, Simplicissimus nos relata o poema que costumava cantar para espantar lobos, poema esse que havia aprendido de sua mãe, mas que, conforme indicado na seção de comentários da edição alemã (p. 801), circulava em um panfleto junto de outros cinco versos. O poema faz uma ode ao camponês, pois é ao seu trabalho de plantar e criar animais que todos, inclusive soldados e imperadores, devem seu alimento. No entanto, não o faz sem sua pitada de ironia, elemento constante na obra. As últimas três estrofes contam que o camponês não sofre de podagra como os nobres e ricos, que, por ser humilde, ganha mais de Deus (uma das possíveis interpretações), e que mesmo o mau costume dos soldados de tomar-lhes os pertences serve o melhor dos intentos de impedir que a arrogância lhes suba à cabeça.

O poema é formado por dez quartetos com versos octossílabos (à exceção de um eneassílabo), na maioria iâmbicos, e as rimas são emparelhadas. Ao invés de adotar apenas um aspecto em detrimento de outros, como no modelo proposto para os sete tipos de tradução poética de Lefevere (1975apud BASSNETT, p. 87), que prevê apenas a preservação da métrica ou esquema rítmico originais, por exemplo, percebemos no texto de Frungillo uma tentativa de conciliar forma e conteúdo, de modo que os versos em português têm nove sílabas (à exceção de um decassílabo), sendo a quarta acentuada, ainda que por vezes sob força de elisão ou hiato. Examinemos as duas últimas estrofes a título de exemplo:

De todo ignoras a vã soberba, De nosso tempo senhora acerba.

Ela de modo algum te seduz,

Para isso Deus te deu tua cruz.

E o mau costume do vil soldado

Nisto também te tem ajudado, Pois teu orgulho não vale um figo Quando ele diz: - O teu vem comigo! (GRIMMELSHAUSEN, 2008, p. 23)

Percebemos que o quarto verso só se encaixa no esquema rítmico se elidirmos o "a" final em "para"("par' isso") e atribuirmos a "tua" duas sílabas Organon, Porto Alegre, v. 31, n. 61, p. 153-175, jul/dez. 2016. 
("tu-a"). Conforme o texto-fonte, os versos iniciam com letra maiúscula, alterações sintáticas próprias do gênero ocorrem, e o último verbo consiste na citação da fala de um soldado, indicada por verbo dicendi e dois pontos:

Der Hoffart bist du sehr befreyt /

Absonderlich zu dieser Zeit /

Und daß sie auch nicht sey dein Herr /

So gibt dir Gott deß Creutzes mehr.

Ja der Soldaten boeser Brauch /

Dient gleichwohl dir zum besten auch /

Daß Hochmut dich nicht nehme ein /

Sagt er: Dein Hab und Gut ist mein.

(GRIMMELSHAUSEN, 2013, p. 25)

Sabemos que Hoffarté antes arrogância, e não soberba, portanto, uma tradução mais literal do primeiro verso seria "tu és/foste libertado da arrogância". Absonderlichpode ser referir tanto a "ser liberado" quanto a "soberba", de modo que duas interpretações são possíveis: ou os camponeses foram "libertados da arrogância, principalmente nos tempos atuais", ou eles foram "libertados da arrogância, peculiar nesses tempos". Percebemos que a tradução mantém, de certa forma, o segundo sentido, e ainda especifica o modo de sua peculiaridade. "E como ela não seja teu senhor", lemos no terceiro verso, então "a ti o Deus da Cruz dá mais", ou "a ti Deus dá mais por causa de tua cruz", ou ainda "a ti Deus dá maior cruz". Ainda que as possibilidades de interpretação sejam diferentes em português, o tradutor também conseguiu, através do último verso, criar diferentes possibilidades de leitura: será a cruz uma punição, ou antes, uma consequência negativa da falta demasiada de soberba? Ou terá Deus dado ao camponês uma outra cruz capaz de seduzi-lo, visto que não o é pela soberba?

Já a última estrofe, sob uma tradução mais literal, poderia ser entendida como "E o péssimo costume do soldado / Também serve a ti para o melhor / Para que a arrogância (ou orgulho) não se apodere de ti / Ele diz: teus pertences e propriedades são meus". Desse modo, vemos que a intenção do soldado do texto-fonte, é, alegadamente, ajudar o camponês e não ser orgulhoso, enquanto sua intenção, no texto-alvo, é tomar-lhe as coisas, independente de isso ferir-lhe o orgulho ou não. Apesar das claras diferenças, em ambos os poemas a atenção se volta para o soldado, que é bem-sucedido, ambos terminam com uma frase de efeito, e ambos mostram que a dita importância dos camponeses não é reconhecida, de modo 
que podemos afirmar que a tradução causa efeito análogo sobre o leitor e cumpre sua função de ode satírica ao camponês, mantendo ainda a forma de poema passível de ser cantado.

Grimmelshausen não hesita em usar dialetos para caracterizar as falas das personagens, e o faz com a mesma naturalidade com que usa latinismos e expressões eruditas. Como pertencem antes ao registro falado, não costumam ter sua escrita sistematizada e estão ligados a uma cultura e a uma geografia próprias, dialetos caracterizam um desafio para o tradutor. Analisemos, primeiramente, um trecho do texto alemão:

Aber indessen wieder zu meiner Heerd zu kommen / so wis-
set / daß ich den Wolff eben so wenig kennet / als meine ei-
gene Unwissenheit selbsten; derowegen war mein Knan mit
seiner Instruction desto fleissiger: Er sagte / Bub biß fleissig /
loß die Schoff nit ze weit vunananger laffen / un spill wacker
uff der Sackpfeiffa / daß der Wolff nit kom / und Schada dau
/ dann he yß a solcher feyerboinigter Schelm und Dieb / der
Menscha und Vieha frisst / un wan dau awer farlaessi ist /
so will eich dir da Buckel arauma (GRIMMELSHAUSEN,
2013, p. 23).

Simplicissimus introduz a fala do pai através de um período longo, com subordinação, e um empréstimo do latim, Instruction, ao passo que poderia ter utilizado uma palavra alemã de uso corrente, como Lehre ou Unterweisung, sendo a última a opção escolhida por Kaiser. Ludwig M. Eichinger (2001, p. 169) mostra que elementos como eich para ich (eu) e he para er (ele) nos permitem localizar uma área relativamente pequena, que pode ainda ser conferida no atlas linguístico MittelrheinischenSprachatlas (EICHINGER, 2001, p. 169).Trata-se do falar de Hessen, região central da Alemanha. A fala do pai, proferida e escrita em dialeto é bastante informal, e contrasta com o modo de narrar de Simplicissimus. Anthony Pim (2000, p. 69) afirma ser a tradução de dialetos um dos limites da traduzibilidade, pois ao perguntar se marcadores de variedades linguísticas devem ser preservadas na tradução, Pim aponta para duas respostas: positiva, pois o que houver de significativo nessas marcas deve ser traduzido, ou negativa, pois os valores de uma variedade não podem ser mapeadas em outra cultura (p. 69). O tradutor brasileiro optou por manter a fala em alemão no corpo do texto, grafá-la em itálico e traduzi-la em nota de rodapé, na língua padrão, utilizando o pronome tu e indicando, entre parênteses, tratar-se o trecho de um dialeto: 
Garoto, sê dedicado, não deixes as ovelhas andarem muito longe umas das outras e toca a gaita com vontade, para que o lobo não se aproxime e provoque danos, pois ele é um gatuno de quatro patas e um ladrão que devora homens e animais, e se fores negligente eu te castigarei o lombo. (Em dialeto de Hesse no original)(GRIMMELSHAUSEN, 2008, p. 20-21).

O pronome escolhido conjugado corretamente talvez diminua a coloquialidade da fala do pai, e, podemos afirmar, até sua falta de instrução formal, no entanto, acentua o caráter de ensinamento transmitido oralmente. Expressões como "provoque danos" e "negligente" também se afastam da coloquialidade, ao passo que "te castigarei o lombo" a acentua, e a indicação do tradutor de tratar-se a fala de um dialeto, também. Já o trecho que introduz a fala do pai utiliza outros recursos para contrastar os registros formal e informal:

Mas, voltando ao meu rebanho, sabei que eu tinha tão pouco conhecimento da existência do lobo quanto da minha própria ignorância; por isso, meu knan dedicou especial atenção em instruir-me. Ele me disse (...) (GRIMMELSHAUSEN, 2008, p. 20).

Ao invés de uma palavra latina, o tradutor adotou o uso de ênclise, e também a conjugação do verbo saber na segunda pessoa do plural atenta para um uso mais controlado da língua, pois, ao invés de "sabei", poderia ter optado por "saibam", que manteria o mesmo grau de formalidade da conjugação do verbo alemão, visto que o pronome da segunda pessoa do plural "ihr" se aproxima mais de vocês", pois "vós" caiu em desuso. Desse modo, percebemos que nem sempre o tradutor consegue causar determinado efeito com os mesmos recursos do texto-fonte ou nos mesmos trechos, mas pode fazê-lo em outras partes através de diferentes meios.

Também Reinhard Kaiser, que publicou sua adaptação para o alemão contemporâneo em 2009, tomou o cuidado de manter as diferenças de registros:

Aber um auf meine Heerde zurückzukommen, so wisset, dass ich den Wolf genauso wenig kannte wie meine eigene Unwissenheit. Deswegen war mein Knan mit seiner Unterweisung umso fleißiger. Er sagte: „Bub, bis fleißig. Loss die Schof nit ze weit vunananger laafen un spill wacker uff der Sackpfeifa, dass der Wolf nit komm und Schada dau, dann hej üss a 
solcher vieraboinigter Schelm und Dieb, der Menscha und Vieha frisst. Un wann du awer fahrlässi bist, so will eich dir da Buckel arauma(GRIMMELSHAUSEN, 2009, p. 20).

Como antes mencionado, Kaiser optou por Unterweisung ao invés de Instruction, palavra já existente no século XVI com esse mesmo sentido, atualmente considerada de estilo elevado, mas ainda assim mais transparente para o leitor alemão do que o vocábulo latino. Percebemos mudanças na parte que introduz a fala do pai: indessen, utilizada como conjunção que introduzia uma oração subordinada no século XVII, é hoje um advérbio, de modo que a opção por um causa o mesmo efeito de fluidez de leitura do trecho do texto-fonte quando de sua publicação. Kaiser também mantém, quase em sua totalidade, a fala do pai, pois a diferença entre fleissig e fleißig, ou entre Wolff e Wolf, ou ainda entre $y ß$ e üss é meramente ortográfica, ou seja, não acarreta mudança de pronúncia. A única diferença significativa é a substituição de feyer por vier (quatro), palavra utilizada no dialeto atualmente. Manter tal trecho quase inalterado nos parece uma boa escolha, pois podemos inferir que, se o leitor de hoje tem alguma dificuldade para entender a fala do pai, o mesmo vale para os leitores do século XVII que desconheciam o dialeto, e para os leitores atuais que o conhecem, a fala até pode soar arcaica, mas é compreensível, e isso se explica pelo fato de dialetos serem mais estáveis quanto à mudança diacrônica.

Cabe aqui comparar a tradução Frungillo à atualização de Kaiser, que se utilizaram da mesma edição alemã (editada por DieterBreuer em 1989) para seu trabalho. Ambos preservam o tom do narrador quando de sua publicação. Tendo em mente que o romance (não como gênero constituído, mas como narrativa em prosa) no século XVII não era considerado um gênero elevado (HEISE apud CARDOZO2009. p. 660), percebemos em Simplicissimus uma leitura fluida e agradável, mesmo quando demonstra sua erudição através de alusões a textos clássicos ou expressões latinas. Desse modo, os textos de Frungillo e Kaiser se aproximam um do outro. Ademais, os dois tradutores se valeram de notas de rodapé e comentários da edição de Breuer.

Frungillo ainda inseriu notas de rodapé de sua autoria, e, na edição brasileira, o artigo que vale de posfácio O Homem, o Mundo e O Homem e o Mundo em tradução, de Maurício Mendonça Cardozo, apresenta uma breve biografia do autor e de sua obra; comenta sua recepção; discute os estudos feitos sobre Simplicissimus quanto a gênero literário, possibilidades de interpretação, apropriação de fontes literárias e repercussão na literatura posterior; 
e, por fim, ressalta o caráter de transformação da obra, defendendo que a constante inconstância de Simplicissimus é uma alegoria do transitório, e esse caráter transformativo representa a tradução. Na Nota do Tradutor, texto de abertura do livro, Frungillo afirma ainda ter utilizado uma tradução para o inglês e uma para o italiano para auxiliá-lo em seu trabalho.

Já Kaiser recorre à uma tradução para o inglês e outra para o francês. Além das notas de Breuer, a edição contempla um texto em formato entrevista, no qual o tradutor fala de suas motivações para traduzir o livro e no que consiste tal tradução. Nele, afirma que as diferenças semânticas de inúmeras palavras e expressões, além de palavras e expressões que caíram em desuso, causam dificuldades para o leitor. A edição contém ainda um texto análogo ao posfácio de Cardozo, intitulado Simplicissimus e o seu criador: Dados biográficos e apontamentos sobre a história da obra. Por fim, apresenta uma lista da bibliografia utilizada.

A edição alemã de DieterBreuer é repleta de notas ao pé da página, bem como apresenta uma seção de notas mais extensas ao final do livro, com 187 páginas. Frungillo selecionou e traduziu notas de ambos os tipos, de modo que referências a outras obras literárias e conhecimento extralinguístico fazem parte da tradução. No primeiro capítulo do segundo livro, por exemplo, a nota referente à obra Preto e branco nos avisa que esse era o título original de SatyrischerPilgram, publicado em 1667, a qual Simplicissimus se refere como autor (p. 115). Já a nota da página 209 explica que o comentário de Simplicissimus faz uma "alusão ao conto-de-fadas $O$ alfaiatezinho valente", e a nota da página 380, “[a]lusão ao Êxodo, cap. 16, vers. 3", é uma das inúmeras notas que indicam referências à Bíblia. Por outro lado, em relação ao "acalanto que lhe [a Wallenstein] cantaram em Eger" (p. 195), a nota de rodapé explica que "Wallenstein foi assassinado em Eger, na Boêmia, no dia 25 de fevereiro de 1634”, e, na página 175, uma nota explica no que consistia a Phisiognomia: "Ciência que procurava reconhecer, nos traços fisionômicos, o caráter de uma pessoa”.

No entanto, Frungilloutilizounotas de rodapé em ainda dois casos: para traduzir falas em dialeto, como mostrado anteriormente, e para explicar sutilezas da língua, como trocadilhos, que não puderam ser resgatadas em português. Ao final do primeiro capítulo, por exemplo, há uma nota indicada para o trecho "Oh vida nobre (vida de burro, dirás talvez)" pg. 18, na qual lemos "Há um trocadilho no original entre edelsLeben (vida nobre), e Eselsleben (vida de burro)... Ou ainda, no capítulo 24, uma nota de rodapé explica a fala de uma personagem, que afirma serem adúlteros aqueles que invadem o pomar e colhem as cerejas antes do proprietário: 
Toda esta passagem se baseia sobre trocadilhos. A palavra Ehebrecher (adúltero) é um composto entre Ehe (casamento) e Brecher, substantivo derivado do verbo brechen (romper, quebrar). Ou seja, um adúltero é alguém que rompe o sacramento do matrimônio. A personagem liga então este ato a "colher antes", ou seja,ehe (antes) brechen(romper, aqui com o significado de colher, arrancar da árvore). Assim, também, por esse raciocínio, Deus, que separa um casal pela morte, rompe o casamento, merecendo, portanto, o nome de Ehebrecher (aqui traduzido literalmente por rompe-uniões) (GRIMMELSHAUSEN, 2008, p. 85).

A nota dá sentido à fala da personagem que, em português, se torna um disparate. Já no capítulo 7, parte do trocadilho é mantido, pois a personagem confunde três palavras parecidas em alemão (Kirche, Kirschee Krieche), que em português se tornam igreja, cereja, e espécie de ameixa (p. 37), e também apresentam semelhanças sonoras. Ainda assim, o tradutor inseriu uma nota de rodapé. Percebemos, portanto, que Frungillo não procura trocadilhos em língua portuguesa para adaptar a cena, mas explica o jogo de palavras que ocorre no texto alemão, se aproximando do que Schleiermacher (1963) descreve como "levar o leitor em direção ao autor".

\section{Conclusão}

Perguntamo-nos, no início do artigo, se Simplicissimus pode ser considerado um romance vanguardista avant la lettre devido à incorporação de inúmeras referências textuais externas, às vezes em forma de colagem, outras vezes de maneira mais trabalhada e digerida. Se compararmos este romance a, por exemplo, obras destacadas da avant-garde como Berlim Alexanderplatz(1929), de Alfred Döblin, ou até a Ulysses(1922),de James Joyce, com seus mix lingüísticos, do dialeto falado nas ruas de Berlim ou Dublin a formas mais arcaicas, bem como citações de trechos de livros, periódicos, notícias ou anúncios, há de fato semelhanças na construção destas obras como recorte de seu tempo. Mas o que Döblin e Joyce encenam em suas obras são a reintrodução de certa qualidade épica, aquilo que Benjamin chamou de "colher os moluscos arremessados na areia" (1986, p. 126), ou seja, a tradição oral-coletiva pré-Gutemberg; porém, como não poderia ser diferente, agora no contexto medial-técnico do início do século $\mathrm{XX}$, os moluscos colecionados pelo poeta épico são de natureza diferente: 
incluem ainda formas orais, mas combinam estas com formas atuais como notícias de jornais, propagandas em forma de out-door, estatísticas e todo tipo de material impresso, bem como trechos de filmes através da técnica de montagem. Assim, estes romances emergem como uma compilação de frações e fragmentos triviais, tais como dicionários, jornais, anedotas contadas em pubs, anúncios, lendas, bem como diversas formas linguísticas históricas coletadas e montadas. Obviamente não se trata de uma imitação do mundo visual, oral e impressiona forma de romance, mas antes de tudo, uma volumosa implosão das estruturas e configurações romanescas, erguendo um monumento deste mundo e, paralelamente, negando-o de modo imponente. Podemos, com todo cuidado, ver Simplicissimus como recorte de sua época, não tanto em um nível autobiográfico de Grimmelshausen, mas como compilação feita de formas orais de comunicação, lembrando aqui o papel do dialeto, mas sobretudo oriundo do médium de comunicação dominante da época, o texto impresso em todas suas variações e variedades. Ao mesmo tempo Grimmelshausen interfere nesse universo construído com o apagar de autoria, com narrativas não confiáveis, com contradições e ambuiguidades, sempre deixando dúvidas e aberturas para múltiplas compreensões ou interpretações. E nesse ponto do enigmático e insolúvel, talvez possamos encontrar algo em comum entre Grimmelshausen e James Joyce, que dizia sobre Ulysses: "I've put in so many enigmas and puzzles that it will keep the professors busy for centuries arguing over what I meant, and that's the only way of insuring one's immortality" (apud ELLMANN, 1982, p. 521).

As referências a outras obras e elementos específicos da época, de difícil resgate ou entendimento na edição original devido à distância histórica, são resgatadas na transposição para o português à medida que o tradutor insere notas de rodapé ou opta por determinadas escolhas lexicais. Sabe-se que toda tradução implica em perdas e ganhos e se, diferente de Kaiser, Frungillo não mantém a seção de comentários finais da edição de Breuer, nem por isso deixa de assinalar ao leitor a riqueza intertextual presente na obra.

\section{REFERÊNCIAS}

AYLETT, Robert P.T. Lies, Damned Lies and a Simplex's Version of the Thruth: GrimmelshausenUnrealiable Narrator. Daphnis 18, 1989, p. 159-177. 
BEINSSEN-HESSE, Silke. Die literarischen Quellen von Grimmelshausens "Simplicissimus". Disponivel em: http://thingsgermanaustralian.blogspot.com.br/2013/07/die-literarischen-quellen-von.html. 03/01/2016

BENJAMIN, Walter. A crise do romance. In: Gesammelte Schriften (G.S.), Volume III.p.230-236. Tradução CelesteRibeiro e Souza, in: BOLLE,W. (Org.) Documentos de Cultura, documentos de Barbárie, São Paulo: Cultrix/ Edusp, 1986, p. 126-129.

BERGHAUS, Peter, BÜRGER, Thomas et al. Simplicius Simplicissimus: Grimmelshausen und seine Zeit. Münster: Landschaftsverband WestfalenLippe, 1976.

BRIE, Renate. Die sozialen Ideen Grimmelshausens, besonders über die Bauern, die armen Leute und die Soldaten. Berlin: Ebering, 1938. BÜRGER, Peter. Teoria de la Vanguardia. Barcelona: EdicionesPeninsula, 1987.

DOMAGALLA, Leo. Der Kalendermann Grimmelshausen und sein Simplicissimus. Würzburg: Konrad Triltsch,1942. EICHINGER, Ludwid M. Regiolektales Srechen in Hans Jakob von Grimmelshausen „Simplicius Simplicissimus"Nicht zuletzt am Beispiel des Niederdeutschen. In: PETERS, Robert. PÜTZ, Horst P. WEBER, Ulrich. (Org.) Vulpis Adolatio. Heidelberg: Universitätsverlag, 2001. p. 165-182. ELLMANN, Richard. James Joyce, 2nd ed. Oxford: Oxford University Press: 1982.

GRIMMELSHAUSEN, Hans Jakob Christoffel von. Simplicissimus teutsch. Frankfurt am Main: Deutscher Klassiker Verlag, 1989. GRIMMELSHAUSEN, Hans Jacob Christoffel von. Der abenteuerliche Simplicissimus Deutsch. Aus dem Deutschen des 17. Jahrhunderts und mit einem Nachwort von Reinhard Kaiser. Frankfurt am Main: Eichborn, 2009.

GRIMMELSHAUSEN, Hans Jakob Christoffel von. O Aventuroso Simplícissimus. Traduzido por Mário Luiz Frungillo. Curitiba: Editora UFPA, 2008.

GUNDOLF, Friedrich. Grimmelshausen und der Simplicissimus. In: WEYDT, Günther (Hrsg.). Der Simplicissimusdichter und sein Werk. Darmstadt: Wissenschaftliche Buchgesellschaft, 1969. HOLZINGER, Walter. Der abentheurlicheSimplicissimus and Sir Philip Sidney's “Arcadia”. In: ColloquiaGermanica Vol. 3 (1969), p. 184-198. HORÁCIO. Arte Poética. Intr., Trad. e Notas por FERNANDES, Rosado. Lisboa: CalousteGulbenkian, 2012. 
KAISER, Reinhard. Grivorschau. Disponível em: $<$ http://www.reinhardkaiser.com/LesesaalNeu/VersammelteWerke/grivorschau.pdf>. 23/01/2016

KÖNNECKE, Gustav. Quellen und Forschungen zur Lebensgeschichte Grimmelshausen II. Weimar:Gesellschaft der Bibliophilen, 1928. KOSCHLIG, Manfred. Das Ingenium Grimmelshausens und das 'Kollektiv'. München: Beck, 1977.

LEFEVERE, André. Translating Poetry, Seven Strategies and a Blueprint. In: BASSNETT, Susan. Translation Studies. New York: Routledge, 2002. p. 87. MAZZARI, Marcus. Dinheiro e violência num monumento literário. Disponível em: <http://www.revistatropico.com.br/tropico/html/textos/3115,1.shl $>.03 / 04 / 2016$

MERZHÄUSER, Andreas. Der Abentheurliche Simplicissimus - Die Begründung des modernen Romans aus dem Geist der Pikareske. Disponível em:

$<$ http://www.g-daf-es.net/lesen_und_sehen/germanistik/merzhaeuser. pdf $>$. 27/12/2015

OEFTERING, Wilhelm Engelbert. Ewig währender Kalender nebst Stükken aus dem jährlichem Wunder-Geschichts-Kalender. München: Langen, 1925.

OTTO, Karl F. A Companion to the Works of Grimmelshausen Rochester New York: Camden House, 2003.

PYM, Anthony. Translating Linguistic Variation: Parody and the Creation of Authenticity. Disponível em <http://usuaris.tinet.cat/apym/on-line/ translation/2000_authenticity.pdf> 28/05/2016 ROSENBERG, Sebastian. Grimmelshausens Werke - Einleitung. Disponível em $<$ http://diglib.hab.de/content.php?dir=edoc/ ed000133\&distype $=$ optional\&metsI $\mathrm{D}=$ edoc_ed000133_introduction $1 \& \mathrm{xml}=$ tei-introduction. $\mathrm{xml} \& \mathrm{xs}=$ =teiintroduction.xsl>. 03/04/2016 ROSENBERG, Sebastian. Satirische Sprache und Sprachreflexion: Grimmelshausen im diskursiven Kontext seiner Zeit., Berlin: de Gruyter, 2015. SCHLEIERMACHER, Friedrich. Ueber die verschiedenen Methoden des Uebersetzens. In: STÖRIG, Hans Joachim (Org). Stuttgart: Goverts, 1963. Disponível em <http://users.unimi.it/dililefi/costazza/programmi/2006-07/Schleiermacher.pdf > 04/06/2016 SCHOLTE, Jan Henrik. Der Simplicissimus. Teusch. Die klassische Urform. Tübingen: Max Niemeyer, 1950. 
STRÄSSLE, Thomas. «Vom Unverstand zum Verstand durchs Feuer» Studien zu Grimmelshausens Simplicissimus Teutsch. Bern: Lang, 2001. WEYDT, Günther. Nachahmung und Schöpfung im Barock. Studien um Grimmelshausen. Bern u. München: Francke, 1968.

Recebido em: 11/06/2016. Aceito em: 04/09/2016. 